\title{
Resistência de pimentão ao PepYMV e PepYMV-Lins e obtenção de híbridos resistentes
}

\author{
Renato Braga ${ }^{1}$, , Marcelo Agenor Pavan $^{2}$ (우
}

\begin{abstract}
${ }^{1}$ Sakata Seed Sudamerica Ltda., Av. Dr Plínio Salgado, 4320, CEP 12906-840, Bragança Paulista, São Paulo, Brasil; ${ }^{2}$ Unesp - Fazenda Experimental Lageado - Av. Universitária n. 3780 CEP 18610-034, Botucatu, São Paulo, Brasil

Autor para correspondência: Renato Braga (renato.braga@sakata.com.br)

Data de chegada: 16/07/2020. Aceito para publicação em: 04/11/2020.
\end{abstract}

$10.1590 / 0100-5405 / 241035$

\section{RESUMO}

Braga, R.; Pavan, M.A. Resistência de pimentão ao PepYMV e PepYMV-Lins e obtenção de híbridos resistentes. Summa Phytopathologica, v.47, n.1, p.21-26, 2021.

O Pepper yellow mosaic virus (PepYMV) é o mais importante Potyvirus infectando plantas do gênero Capsicum no Brasil. Perdas podem chegar a $100 \%$ caso a infecção ocorra no início do cultivo. A resistência genética é a principal forma de controle desta virose. Em 2009 um novo isolado denominado PepYMV-Lins foi detectado quebrando a resistência genética das cultivares comerciais. Este trabalho visou buscar fontes de resistência a este novo isolado, estudar a herança da resistência, incorporar em linhas elites e criar híbridos de pimentões resistentes e com boa performance agronômica. Dentre os acessos do banco de germoplasma da empresa Sakata, foram encontradas seis pimentas e dois pimentões que portavam resistência conjunta aos isolados PepYMV e PepYMV-Lins. Estes dois últimos foram escolhidos para continuar os trabalhos de introdução de resistência. O estudo de herança apontou que a resistência genética nos dois acessos de pimentões é monogênica e recessiva. Eles foram cruzados com as linhagens elites de pimentões com o objetivo de criar híbridos comerciais do tipo cônico. Para acelerar o trabalho de melhoramento foi utilizada a técnica de criação e estabilização de linhagens via duplo haploide. As novas linhagens geradas por esta metodologia foram cruzadas para geração de híbridos. Os novos híbridos mostraram-se resistentes aos isolados PepYMV e PepYMV-Lins. Dois deles (AF23571 e AF23579) foram identificados com estabilidade agronômica e resistência. Testes em larga escala mostraram que o AF23579 foi o que apresentou melhor performance. Este híbrido está disponível comercialmente no mercado brasileiro de sementes de pimentão com o nome de Nocaute.

Palavras-chave:Pepper yellow mosaic virus, virose, Nocaute

\section{ABSTRACT}

Braga, R.; Pavan, M.A. Pepper resistance to PepYMV and PepYMV-Lins and development of resistant hybrids. Summa Phytopathologica, v.47, n.1, p.21-26, 2021.

Pepper yellow mosaic virus (PepYMV) is the most important Potyvirus infecting plants of Capsicum genus in Brazil. Losses can reach 100\% if the infection occurs at the beginning of cultivation. Genetic resistance is the major method to control this disease. In 2009, a new isolate called PepYMV-Lins was detected breaking the genetic resistance of commercial varieties. This study aimed to search for sources of resistance to this new isolate, investigate the inheritance of resistance, incorporate in elite inbred lines and develop new hybrids of resistant peppers showing good agronomic performance. Among the accessions of the germplasm bank of Sakata Company, there were six hot peppers and two sweet peppers that carried combined resistance to PepYMV and PepYMV-Lins isolates. The latter two were chosen to continue the study of resistance introduction. The inheritance study indicated that the genetic resistance of the two sweet pepper accessions is monogenic and recessive. They were crossed with the Company's elite pepper inbred lines with the aim of developing commercial hybrids of the conic type. To accelerate the breeding study, the technique of development and stabilization of lines via double-haploid was used. The new inbred lines obtained through this methodology were crossed to generate hybrids. The newly developed hybrids were resistant to PepYMV and PepYMV-Lins isolates. Two of them (AF23571 and AF23579) were identified to have high agronomic stability and resistance. Large-scale tests indicated that AF23579 had the best performance. This hybrid is commercially available in the Brazilian market of sweet pepper seeds, where it is named 'Nocaute'.

Keywords: Pepper yellow mosaic virus, viral disease, 'Nocaute'

O gênero Potyvirus tem como membros muitas espécies de importância para a cultura do pimentão (Capsicum annuum L.). O Potato virus Y (PVY) foi, durante muitos anos, a virose mais importante da cultura no Brasil e só deixou de acumular perdas significativas quando, na década de 1970, o Instituto Agronômico de Campinas (IAC) lançou os primeiros cultivares resistentes (22 e 23). Esse vírus evoluiu ao longo do tempo e, nos anos de 1980, tornou-se novamente importante pelo surgimento da estirpe $\mathrm{PVY}^{\mathrm{m}}$ ou PVY-1,2 que foi capaz de quebrar os cultivares resistentes (4). Incialmente esta estirpe foi reportada na região de Elias Fausto-SP, sendo rapidamente disseminada para outras regiões produtoras de pimentão do Brasil. Em 1994 um novo híbrido portando resistência às estirpes de PVY conhecidas à época foi lançado com o nome Magali R pela empresa Agroflora (atual Sakata Seed Sudamerica Ltda.), tornando-se o principal cultivar de pimentão do mercado brasileiro por mais de 20 anos.

Ao longo do tempo, as estirpes de PVY receberam diversas denominações como a proposta por Nagai em 1993: PVYw ${ }^{\mathrm{w}} \mathrm{PVY}^{\mathrm{f}}$ e PVY $^{\mathrm{ft}}$ (23) e a sugerida por Gébre-Selassie em 1985: PVY-0, PVY-1, PVY-1-2 (10). Esta última sequência é a mais aceita e comumente utilizada. Em 2002, com base na análise genômica do vírus, a estirpe $\mathrm{PVY}^{\mathrm{m}}$ mereceu o status de espécie sendo nomeada Pepper yellow mosaic virus (PepYMV) e considerada como o membro mais importante dos Potyvirus da cultura do pimentão no Brasil (15). Em 2009 foi relatada outra estirpe de PepYMV na região produtora da cidade de Lins (SP) sendo denominada PepYMV-Lins (13). Esta nova estirpe foi capaz de superar os genes de resistência das cultivares comerciais de pimentão. Em uma ampla coleta realizada por Moura e colaboradores em 2011 foram identificadas cinco diferentes estirpes 
de PepYMV, sendo classificadas como $2^{1} \cdot 2^{2} ; 2^{1} \cdot 2^{3} ; 2^{1} \cdot 2^{2} \cdot 2^{3} ; 2^{1} \cdot 2^{3} .4$ e $2^{1} \cdot 2^{2} .2^{3} .4$ (21). Nesta classificação o PepYMV-Lins foi reclassificado para PepYMV $-2^{1} \cdot 2^{2} \cdot 2^{3}$.

No Brasil, ao longo dos anos, os pesquisadores identificaram e introgrediram genes de resistência para controlar os Potyvirys que acometem a cultura do pimentão. Os genes mais utilizados pelos programas de melhoramento são os recessivos $p v r 2^{+}, p v r 2^{1}, p v r 2^{2}$, $p v r 2^{3}, p v r 2^{4}$ e os dominantes $P v r 4$ e $P v r 7$ (1, 5 e 10). Exemplo de acessos são o genótipo Yolo Wonder, que carrega o gene $p v r 2^{+}$, Yolo Y o gene $p v r 2^{1}$, Florida VR-2 o gene $p v r 2^{2}$, Serrano Vera Cruz o gene $p v r 2^{4}$, Puerto Rico Wonder o gene $p v r 2^{3}$ e Criollo de Morellos os genes $p v r 2^{3}$ e $P v r 4$ (1, 2 e 5). O gene $P v r 4$ é amplamente utilizado pelas empresas de melhoramento de hortaliças por ser monogênico, dominante e por conferir resistência a muitos isolados de PVY e PepYMV. Contudo, alguns isolados, como o PepYMV-Lins (PepYMV-2 ${ }^{1} .2^{2} .2^{3}$ ), PepYMV $-2^{1} .2^{3} .4$ e PepYMV $-2^{1} .2^{2} .2^{3} .4$ são capazes de quebrar esta resistência. Bento e colaboradores estudando fontes de resistências ao PepYMV encontraram dois acessos em C. baccatum e sete na espécie $C$. chinense, e não encontraram acessos resistentes em $C$. annuum e $C$. frutescens (3). Estas fontes de resistência são de difícil utilização por apresentarem herança poligênica. Moura e colaboradores descreveram que a fonte de pimenta Serrano Vera Cruz, contendo o gene $p v r 2^{4}$, apresenta resistência para algumas das principais estirpes de PepYMV encontradas no Brasil, incluindo a PepYMV-Lins (21).

A técnica de duplo haploide pode acelerar a introdução de genes de resistência e o desenvolvimento de linhas homogêneas utilizadas na produção de híbridos (7 e 18). O primeiro relato deste tipo de cultivo foi de Haberlandt em 1902 descrito por Krikorian \& Berquam (17). Depois disso muito se estudou visando aprimorar o meio de cultivo das células. Neste processo de aprimoramento foram descobertos os fitormônios o que facilitou aplicações do cultivo in vitro de células vegetais $(16,26 \mathrm{e}$ 27). No gênero Capsicum os primeiros trabalhos utilizando esta técnica foram para introduzir características desejáveis, como resistências a patógenos e a estresses abióticos de espécies selvagens para espécies cultivadas (24). Esta foi empregada no presente trabalho para acelerar a transferência da resistência ao PepYMV para linhagens de pimentão.

\section{MATERIAL E MÉTODOS}

Os experimentos para seleção de fonte de resistência, produção de duplo haploide, produção dos híbridos e seleção agronômica foram feitos nos anos de 2015 a 2017 na Estação Experimental da Sakata Seed Sudamerica localizada em Bragança Paulista, SP (EEBP).

\section{Seleção de fontes de resistência a PepYMV e PepYMV-Lins}

O banco de germoplasma de Capsicum da Sakata Seed Sudamerica possuía em outubro de 2014 mais de 22.700 acessos ativos de pimentas e pimentões. Trinta deles já haviam sido identificados como resistentes ao PepYMV e foram selecionados para este trabalho. Destes 30, cinco pertenciam a espécie $C$. baccatum, três a $C$. frutensis, seis a $C$. chinense e dezesseis a C. annuum. Além dessas espécies também foram testados os principais híbridos comerciais de pimentão do Brasil que possuem resistência ao PepYMV (Magali R, Dahra R, Dahra RX, Rubia R da Sakata; Supremo e Impacto da Seminis; Gaston da Syngenta e Mayara da Hortec).

As estirpes PepYMV e PepYMV-Lins, foram inoculadas nos 30 acessos selecionados do banco de germoplasma e nos híbridos comerciais para localizar fontes de resistência as duas estirpes. Elas foram previamente caracterizadas (19) e são utilizadas pela empresa
Sakata Seed Sudamerica em ensaios para seleção de plantas resistentes a essas viroses. Dezesseis plantas de cada genótipo foram inoculadas com as duas estirpes virais, sendo oito com PepYMV e oito com PepYMVLins. Foram realizadas duas inoculações, sendo a primeira 25 dias após a semeadura na primeira folha definitiva e a segunda, sete dias após a primeira, na segunda folha definitiva. As inoculações foram feitas de acordo com protocolo descrito por Truta e colaboradores (25). Foi utilizado extrato vegetal infectado e tamponado em fosfato de potássio $0,01 \mathrm{M}$ a pH 7,0 e a abrasão mecânica foi feita com carbeto de silício (Carborundum ${ }^{\circledR}$ ) a 600 mesh. Como testemunha foram utilizadas as cultivares Magali R (resistente a PepYMV e suscetível a PepYMVLins), Ikeda (suscetível a PepYMV e a PepYMV-Lins) e Serrano Vera Cruz (resistente a PepYMV e a PepYMV-Lins). As plantas foram mantidas em estrutura metálica com cobertura de plástico difusor e antivírus e com fechamento lateral com tela de sombreamento com $50 \%$ de transparência. A avaliação ocorreu 15 dias após a inoculação quando as testemunhas suscetíveis mostraram 100\% das mudas com sintomas. As mudas foram avaliadas quanto à presença ou ausência de sintomas (mosaico e deformação foliar).

Cruzamento das fontes de resistência com linhagens elites e estudo da herança genética da resistência ao PepYMV e PepYMVLins

As duas melhores fontes de resistência a PepYMV e PepYMVLins encontradas na fase 1 e que apresentaram melhores qualidades agronômicas em experimentos previamente conduzidos na EEBP foram cruzadas com 20 linhagens elites (linhagens com qualidade superior usadas para produção de híbridos) de pimentão tipo cônico para obtenção de populações candidatas para criação de duplo haploides. As linhas resistentes foram utilizadas como progenitores masculinos, enquanto as linhas elites como progenitor feminino. Para os cruzamentos foram utilizadas dez plantas de cada genitor masculino cruzadas com quatro plantas de cada genitor feminino com emasculação de flores no mesmo dia. Os cruzamentos foram realizados em estrutura metálicas tipo arco com cobertura de plástico difusor e antivírus e fechamento lateral com tela com $50 \%$ de transparência. Os híbridos oriundos destes cruzamentos foram cultivados em ambiente protegido tipo telado com estrutura metálica e cobertura e fechamento lateral com tela com $70 \%$ de transparência para evitar polinização cruzada. Foram selecionados aqueles que apresentaram melhor performance agronômica para produção de linhas homogêneas via técnica de duplo haploide. Esses híbridos foram autofecundados para criação das populações F2 ao mesmo tempo que foram retrocruzados com as fontes doadoras da resistência e com as linhagens elites para formarem as populações $\mathrm{RC} 1$ doador (doador da resistência) e RC1 recorrente (ótimas características agronômicas). Essas populações foram necessárias para as análises do teste de herança. Cada estirpe do vírus foi inoculada em 32 plantas da linhagem elite suscetível, da fonte resistente e da população $\mathrm{F} 1$ entre a linhagem elite suscetível e a fonte resistente. Para as populações F2 do cruzamento entre a linhagem elite e a fonte resistente, $\mathrm{RC} 1$ recorrente e $\mathrm{RC} 1$ doador, foram utilizadas 162 plantas para cada vírus. As inoculações com PepYMV e PepYMV-Lins seguiram o protocolo descrito no item anterior.

\footnotetext{
Duplo haplóides - Coleta de anteras e produção de linhagens duplo haploides

A produção de duplo haploide foi realizada no Laboratório de Cultura de Tecido da Sakata, segundo protocolos de Dumas de Vaulx et al. (6), Evans \& Sharp (8) e Horsch et al. (14) otimizados pela empresa. Foram coletadas anteras dos híbridos produzidos entre as
} 
duas melhores fontes de resistência a PepYMV e PepYVM-Lins com as linhas elites de pimentão tipo cônico. O início da coleta ocorreu logo após o aparecimento dos botões florais quando as sépalas tinham o mesmo comprimento das pétalas. Isto é importante para que a maioria dos micrósporos estejam na fase uninucleada. Após a coleta, os botões florais foram mantidos em geladeira por $24 \mathrm{~h}$. Na sequência foram desinfestados com água deionizada, solução de detergente $1 \%$ por 20 segundos, álcool $70 \%$ por 20 segundos, hipoclorito de sódio $2,5 \%$ (v/v de cloro ativo) por dois minutos e novamente água deionizada e autoclavada. Os explantes foram cultivados em meio de cultura até o aparecimento de embriões/plântulas. A confirmação da ploidia e da duplicação do haploide foram realizadas via citômetro.

As plântulas obtidas em laboratório foram aclimatadas em casa de vegetação com cobertura de policarbonato com temperatura, umidade e luminosidade controladas. Após a rustificação das plântulas, foi feita análise via citômetro para conferir quais mudas eram haploides e quais eram diploides. As plântulas diploides foram descartadas e as haploides tratadas com colchicina $0,2 \%$ para duplicação da haploidia criando assim plântulas duplo haploide com homozigose absoluta. As plântulas foram novamente avaliadas via citômetro para confirmação da transformação de haploides para duplo haploide. As mudas duplo haploides, oriundas de mudas haploides tratadas com colchicina, foram clonadas, a partir de segmentos de caule, e transplantadas para vasos plásticos contento substrato de casca de pinus e transferidas para casade-vegetação para realização das inoculações com os vírus PepYMV e PepYVM-Lins para confirmação da resistência. As inoculações com as duas estirpes virais foram feitas em experimentos separados, usando as mudas clonadas para evitar sinergismo de sintoma de uma estripe para outra e seguiram o mesmo protocolo descrito no primeiro item do Material e Métodos.

Seleção agronômica das melhores linhagens e desenvolvimento de híbridos de pimentão com potencial agronômico e resistência a PepYMV e PepYMV-Lins

As plântulas dos genótipos resistentes à ambas as estirpes virais foram transplantadas em telados para seleção de qualidade agronômica. Foi feito experimento comparativo com as principais testemunhas comerciais do mercado (Dahra R, Dahra RX, Rubia R, Magali R, Mayara, Supremo, Gaston e Impacto) que também foram inoculadas e avaliadas para a resistência ao PepYMV-Lins, além das características de arquitetura de planta, formato, tamanho de frutos e potencial produtivo. Para este experimento foram utilizadas oito plantas de cada testemunha.

As linhagens duplo haploides, resistentes as viroses e com qualidade agronômica superiores, foram cruzadas entre si para obtenção de novos híbridos. Estes híbridos foram testados utilizando como padrões os híbridos comerciais de melhores qualidades agronômicas do mercado. Os híbridos experimentais com superioridade agronômica e resistência ao PepYMV e ao PepYMV-Lins foram determinados como candidatos para se tornarem comerciais atendendo assim o objetivo de fornecer ao mercado brasileiro uma cultivar com múltipla resistência a PepYMV e PepYMV-Lins. Esses híbridos foram indexados novamente com ambos os vírus para confirmação da resistência, seguindo o mesmo protocolo de inoculação descrito no primeiro item de Material e Métodos.

\section{RESULTADOS}

Seleção de fontes de resistência a PepYMV e PepYMV-Lins

As testemunhas comerciais incluídas no experimento para seleção de genótipos com resistência ao PepYMV e PepYMV-Lins, reagiram de acordo com o esperado, sendo resistentes ao PepYMV e suscetíveis ao PepYMV-Lins. Dos trinta genótipos previamente selecionados no banco de germoplasma da Sakata por serem resistentes ao PepYMV e por apresentarem divergência genética, seis pimentas (AF19057, AF19059, AF19060, AF19061, AF19062 e o AF19064) e duas linhagens de pimentões da espécie C. annuum (AF17200 e AF17201) mostram-se resistentes também ao PepYMV-Lins (Tabela 1). Esses dois acessos de pimentões, que são do tipo cônico, também apresentaram qualidade agronômica de planta, de fruto e de produção próxima aos híbridos comerciais. Como um dos objetivos do trabalho era o rápido desenvolvimento de híbridos resistentes as duas estirpes virais, os dois pimentões foram selecionados para os cruzamentos com linhagens elites, estudo de herança, criação de linhas (duplo haploides) e produção de novos híbridos.

Cruzamento das fontes de resistência com linhagens elites e estudo da herança genética da resistência ao PepYMV e PepYMV-Lins

As linhagens de pimentões AF17200 e AF17201 cruzadas com as vinte linhas elites da empresa produziram 40 híbridos F1. Destes, após análise de características agronômicas foram selecionados os dez que apresentaram melhor padrão de planta, tamanho e formato de frutos e produtividade. Os dez híbridos foram autofecundados para geração F2 e seus respectivos retrocruzamentos (doador e recorrente).

As gerações F1 e F2 de cada híbrido e os retrocruzamentos (RC1 para o doador e RC1 para o recorrente) foram submetidas a inoculação com os dois vírus. As testemunhas utilizadas no ensaio comportaram-se como o esperado. Ikeda foi suscetível a ambos os vírus; Magali R foi resistente ao PepYMV, mas suscetível ao PepMY-Lins e Serrano Vera Cruz foi resistente a ambos os vírus. Os dez híbridos F1 foram suscetíveis ao PepYMV-Lins, as gerações F2 destes híbridos apresentaram segregação de três plantas suscetíveis ao PepYMV-Lins para uma planta resistente (Figura 1). Os retrocruzamentos dos híbridos para a fonte de resistência apresentaram segregação de uma planta resistente para o PepYMV-Lins para uma planta suscetível e os retrocruzamentos dos híbridos para as linhas elites mostraram que todas as plantas foram suscetíveis. Foi constatado também que toda planta resistente ao PepYMV-Lins também era resistente ao PepYMV. Com estes padrões de segregações fica evidenciado que a herança para o PepYMV-Lins é monogênica e recessiva sendo obrigatório o cruzamento de duas linhas resistentes para desenvolvimento de híbridos resistentes.

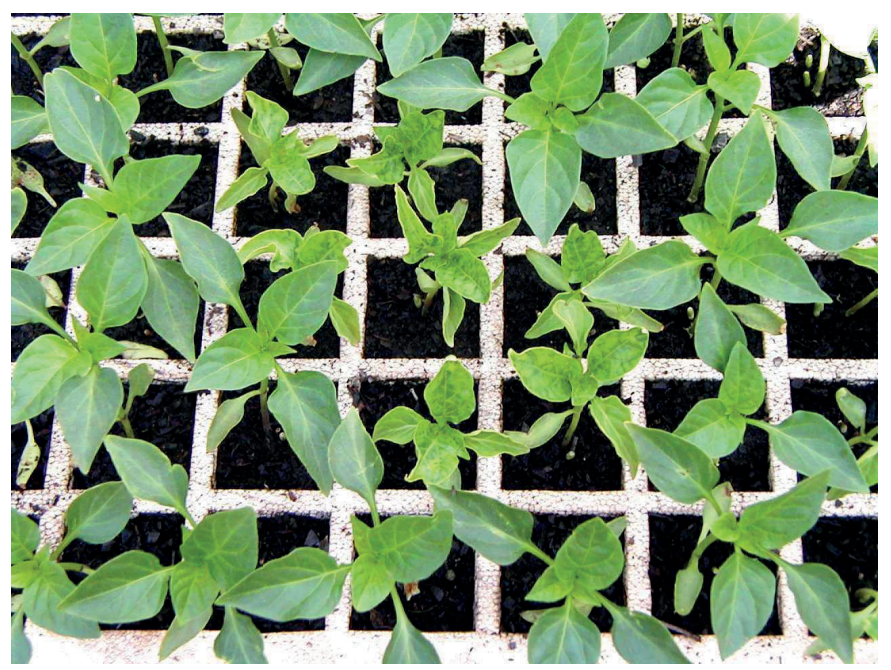

Figura 1. Segregação de plantas resistentes e suscetíveis da população F2 do cruzamento entre linhas elites e fontes de resistência ao PepYMV-Lins. É possível observar plantas com deformação e mosaico e plantas sem sintoma viral. 
Tabela 1. Reação dos genótipos de Capsicum para os isolados dos vírus PepYMV e PepYMV-Lins

\begin{tabular}{|c|c|c|c|c|c|c|c|}
\hline Código/ Nome & Espécie & PepYMV & PepYMV-Lins & Código/ Nome & Espécie & PepYMV & PepYMV-Lins \\
\hline AF 17200 & C. аппиит & $\mathrm{R}$ & $\mathrm{R}$ & AF19070 & C. baccatum & $\mathrm{R}$ & S \\
\hline AF17201 & C. annuum & $\mathrm{R}$ & $\mathrm{R}$ & AF19071 & C. апnиuт & $\mathrm{R}$ & S \\
\hline AF17202 & C. annuиm & $\mathrm{R}$ & $\mathrm{S}$ & AF19072 & C. annuum & $\mathrm{R}$ & $\mathrm{S}$ \\
\hline AF17203 & C. annuит & $\mathrm{R}$ & S & AF19073 & C.апnиuт & $\mathrm{R}$ & S \\
\hline AF19053 & C. baccatum & $\mathrm{R}$ & S & AF19074 & C. апnиит & $\mathrm{R}$ & $\mathrm{S}$ \\
\hline AF19054 & C. baccatum & $\mathrm{R}$ & S & AF19075 & C. annuит & $\mathrm{R}$ & S \\
\hline AF19055 & C. baccatum & $\mathrm{R}$ & S & AF19076 & C. апnuит & $\mathrm{R}$ & S \\
\hline AF19056 & C. chinense & $\mathrm{R}$ & S & AF19077 & C. апnиuт & $\mathrm{R}$ & S \\
\hline AF19057 & C. frutescens & $\mathrm{R}$ & $\mathrm{R}$ & AF19078 & C.апnиит & $\mathrm{R}$ & S \\
\hline AF19059 & C. baccatum & $\mathrm{R}$ & $\mathrm{R}$ & AF19079 & C. апnиит & $\mathrm{R}$ & S \\
\hline AF19060 & C. frutescens & $\mathrm{R}$ & $\mathrm{R}$ & Dahra-R & C. annuиm & $\mathrm{R}$ & S \\
\hline AF19061 & C. chinense & $\mathrm{R}$ & $\mathrm{R}$ & Dahra-RX & C. annuum & $\mathrm{R}$ & S \\
\hline AF19062 & C. chinense & $\mathrm{R}$ & $\mathrm{R}$ & Rubia-R & C. апnиит & $\mathrm{R}$ & $\mathrm{S}$ \\
\hline AF19063 & C. chinense & $\mathrm{R}$ & $\mathrm{S}$ & Supremo & C. апnиит & $\mathrm{R}$ & S \\
\hline AF19064 & C. chinense & $\mathrm{R}$ & $\mathrm{R}$ & Impacto & C. апnичт & $\mathrm{R}$ & S \\
\hline AF19065 & C. апnиum & $\mathrm{R}$ & $\mathrm{S}$ & Gaston & C. апnиum & $\mathrm{R}$ & S \\
\hline AF19066 & C. annuum & $\mathrm{R}$ & $\mathrm{S}$ & Mayara & C. апnиum & $\mathrm{R}$ & $\mathrm{S}$ \\
\hline AF19067 & C. annuum & $\mathrm{R}$ & S & Ikeda & C. annuum & $\mathrm{S}$ & S \\
\hline AF19068 & C. chinense & $\mathrm{R}$ & S & Magali-R & C. апnиит & $\mathrm{R}$ & S \\
\hline AF19069 & C. frutescens & $\mathrm{R}$ & $\mathrm{S}$ & Serrano Vera Cruz & C. аппиит & $\mathrm{R}$ & $\mathrm{R}$ \\
\hline
\end{tabular}

Produção de linhagens duplo haploides e seleção de resistência conjunta ao PepYMV e PepYMV-Lins

Dos botões florais coletados a partir dos dez híbridos selecionados nos ensaios de resistência e performance agronômica, cinco foram regenerados, gerando novas linhagens. Análises por citômetro confirmaram a haploidia. Após a aplicação de colchicina o material genômico foi novamente duplicado, produzindo plantas duplo haploides, com o máximo de homozigose possível.

Os clones das cinco plantas aclimatadas foram submetidos a inoculação com os dois vírus de forma individualizada e foram resistentes a ambos.

Desenvolvimento de híbridos com potencial agronômico e resistência a PepYMV e PepYMV-Lins

A partir do cruzamento entre si das cinco linhas duplo haploides foram produzidos 20 híbridos F1. Todos eles foram resistentes aos vírus PepYMV e PepYMV-Lins. Dois híbridos experimentais, sendo eles os AF23571 e AF23579 (Figura 2), que apresentaram superioridade em relação as testemunhas comerciais foram testados em áreas de produção comercial de pimentão (dados não apresentados). O AF23579 foi o que atingiu os melhores resultados. Este híbrido encontra-se comercialmente disponível no mercado brasileiro com o nome Nocaute.

\section{DISCUSSÃO}

A resistência genética, quando possível de se utilizar, é a alternativa mais eficaz e econômica contra patógenos que prejudicam a produção de plantas $(11,12,19)$. Gera redução de custos, faz com que a produção seja mais fácil e reduz a necessidade de uso de defensivos o que acarreta menor contaminação do ambiente, do produtor e do consumidor. No caso estudado, foi possível encontrar e incorporar rapidamente a resistência genética a PepYMV e PepYMV-Lins em híbridos com alto potencial agronômico e produtivo.

A rápida incorporação da resistência em linhagens elites e a posterior criação de híbridos com potencial de comercialização foi possível porque a herança genética da resistência era de certa forma simples (um gene recessivo) e pelo uso da técnica de duplicação de ploidia (duplo haploide).

A técnica de produção de linhas a partir de duplo haploide não 

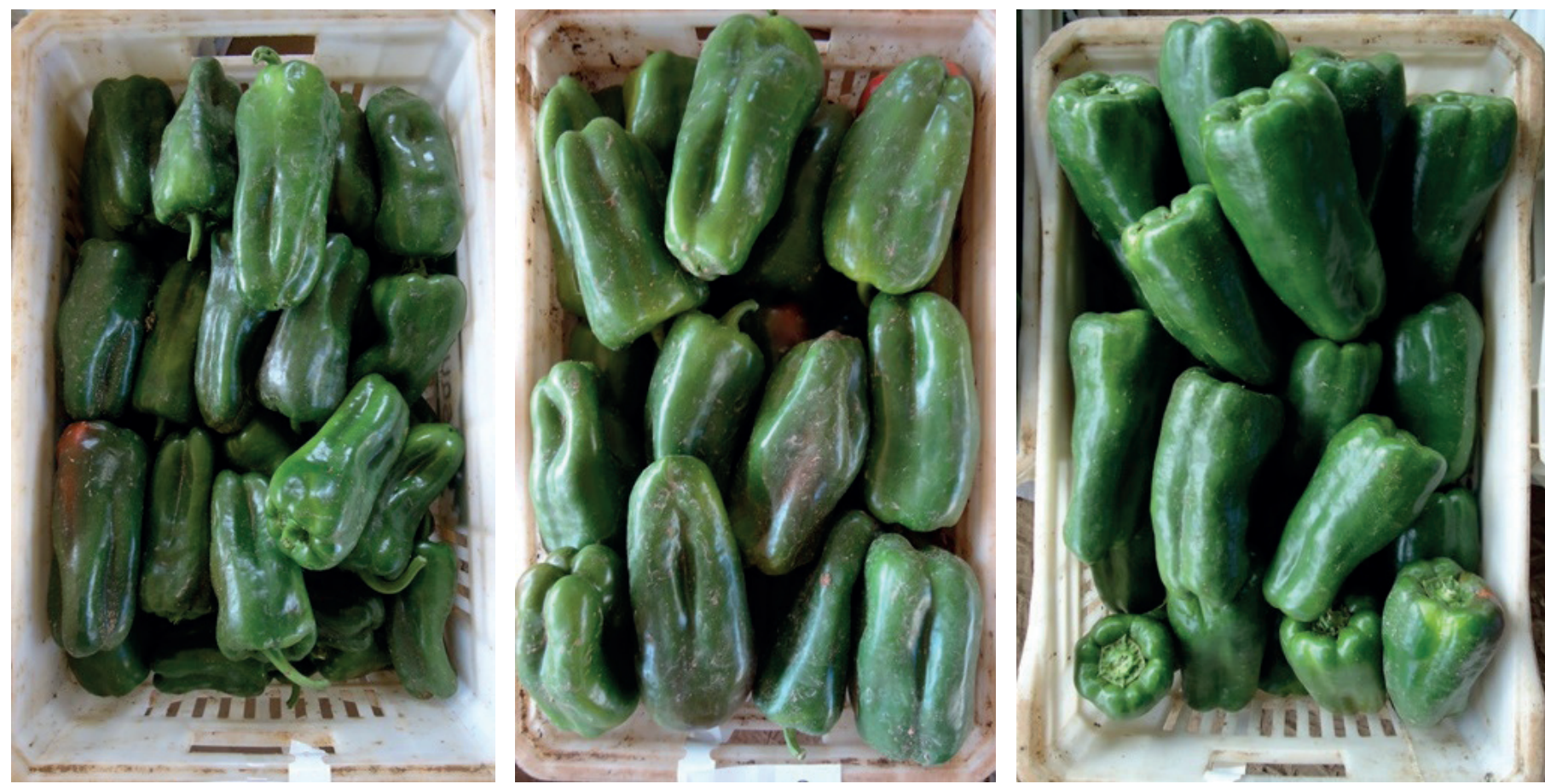

Figura 2. Da esquerda para direita: Híbrido Magali-R padrão de mercado, híbridos AF23571 e AF23579. Esses dois últimos apresentam superioridade em produção e qualidade de frutos (formato e tamanho), além de resistência a PepYMV e PepYMV-Lins. O AF23579 recebeu o nome comercial de Nocaute.

é considerada nova, mas sua utilização no Brasil para produção de híbridos melhorados de hortaliças é relativamente recente e pouco explorada. O uso desta técnica permite introduzir mais rapidamente um gene de interesse em híbridos comerciais (9), reduzir os custos do melhoramento, promover soluções mais rápidas aos produtores e antecipar as receitas por parte das empresas que fazem melhoramento genético. Utilizando a técnica convencional de incorporação de genes de interesse para as linhas elites seria preciso percorrer oito ciclos de seleção, incluindo cinco retrocruzamentos para retornar a $98 \%$ de similaridade a linhagem elite e mais ciclos de seleção e inoculação com o vírus e de seleção agronômica para estabilização da nova linhagem elite criada. Neste trabalho, a incorporação da resistência em linhagens elites, feita a partir da utilização da técnica de duplo haploide, reduziu significativamente o tempo para obtenção da linhagem melhorada. Foram necessários apenas dois ciclos para a geração das linhas, que incluiu o cruzamento das fontes de resistência com as linhas elites e o crescimento das linhas após a duplicação do seu genótipo. Além de acelerar o processo de melhoramento genético, esta técnica consegue gerar linhas puras o que não seria possível utilizando o melhoramento convencional. Assim fica evidenciado a importância de incorporação de novas técnicas e ferramentas biotecnológicas no melhoramento convencional, reduzindo custos e acelerando os resultados (20).

A resistência genética aos vírus PepYMV e PepYMV-Lins encontrada nas duas linhagens de C. апnиит, conforme estudo de herança realizado, é controlado por um gene monogênico e recessivo. Por possuir caráter monogênico, torna o trabalho de melhoramento genético e incorporação da resistência mais fácil. Contudo por ter expressão recessiva, requer que o gene seja incorporado em ambas as linhas para produção de híbrido resistente. Possivelmente o gene presente nas linhas de C. annuum, usadas neste trabalho como fontes de resistência seja o $p v r 2^{4}$. Para melhor elucidação da resistência presente nos híbridos AF23571 e AF23579 tornam-se necessários testes com marcadores moleculares para verificar se essa resistência é conferida por um dos nove alelos descritos do gene $p v r$ ou ainda se trata de um novo alelo/gene.

Até então, os híbridos comercializados no Brasil eram resistentes apenas ao PepYMV (anteriormente denominado PVY Ym ou PVY 1-2). PepYMV é um vírus disperso em todo território nacional e já foi responsável por grandes perdas na cultura do pimentão. A introdução desses híbridos no mercado brasileiro foi um grande alívio a toda cadeira produtiva dessa hortaliça, já que perdas foram minimizadas e custos reduzidos. Com o surgimento da nova estirpe PepYMVLins houve novamente uma grande preocupação quanto a dispersão deste vírus e que as perdas, ora no passado, voltassem a acontecer. $\mathrm{O}$ uso conjunto de trabalhos envolvendo técnicas de melhoramento genético, de fitopatologia e de cultura de tecido foram suficientes e adequadas para disponibilizar rapidamente ao mercado nacional o híbrido AF 23579, que ganhou o nome comercial de Nocaute. Este híbrido carrega características agronômicas altamente desejadas e alto nível de resistência ao PepYMV e ao PepYMV-Lins (também denominada estirpe $\left.2^{1} \cdot 2^{2} \cdot 2^{3}\right)$. PepYMV-Lins ainda está restrita a algumas regiões brasileiras de produção de pimentas e pimentões, mas tem alto potencial de se disseminar por possuir, assim como o PVY e o PepYMV, grande gama de plantas hospedeiras (25), além de inseto vetor (pulgão) altamente eficiente na transmissão (3). Os experimentos de desenvolvimento e confirmação de performance dos híbridos Nocaute (AF23579) e AF23571, nas regiões Sul, Sudeste, Centro Oeste e Nordeste do Brasil mostraram resultados muito animadores quanto a resistência, não sendo encontrada nenhuma planta com sintoma de Potyvirus. Isto mostra a grande estabilidade da resistência das fontes encontradas e dos híbridos criados com uso destas fontes. O híbrido AF23579 foi escolhido para se tornar comercial pois mostrou-se mais estável quanto as características de fruto e produtividade nos trabalhos de validação de performance com plantio em larga escala (dados não apresentados). Novos trabalhos de inoculação e seleção com as demais estirpes de Potyvirus já relatadas no Brasil $\left(2^{1} \cdot 2^{2} ; 2^{1} \cdot 2^{3} ; 2^{1} \cdot 2^{2} \cdot 2^{3}\right.$; 
$\left.2^{1} .2^{3} .4 ; 2^{1} .2^{2} .2^{3} .4\right)$ precisam ser feitos para confirmar a estabilidade da resistência desses híbridos, frente a essas estirpes bem como o acompanhamento da expressão da resistência nos campos de cultivo em diferentes regiões do Brasil

A partir dos trabalhos realizados no presente estudo, foi possível ofertar ao mercado brasileiro de hortaliça um híbrido comercial que agrega valor agronômico a alto nível de resistência a PepYMV e PepYMV-Lins, duas das principais viroses do pimentão.

\section{AGRADECIMENTOS}

Os autores agradecem a Sakata Seed Sudamerica por disponibilizar germoplasma e condições necessárias para o desenvolvimento do projeto e a FCA da Unesp - campus Botucatu, por acolher o primeiro autor em seu quadro de doutorandos.

\section{REFERÊNCIAS}

1. Arnedo, A.A.M.; Arteaga, L.M.; Ortega, R. Response of Serrano Criollo de Morelos-334 to PVY pathotypes. Capsicum and Eggplant Newsletter, Turim, n.17, p.105-109, 1998

2. Arteaga, L.M., Andres, A.M., Ortega, G.R. New Potato virus Y pathotype in pepper. Capsicum and Eggplant Newsletter, Turim, n.16, p.85-86, 1997.

3. Bento, C.S.; Rodrigues, R.; Zerbini Júnior, F.M.; Sudré, C.P. Sources of resistance against the Pepper yellow mosaic virus in chili pepper. Horticultura Brasileira, Brasília, v.27, n.2, p.196-201, 2009.

4. Boiteux, L.S.; Cupertino, F.P.; Silva, C.; Dusi, A.N.; Monte-Nesich, D.C.; Van Der Vlugt. R.A.A. Resistance to Potato virus $Y$ (pathotype 1-2) in Capsicum annuum and Capsicum chinense is controlled by two independent major genes. Euphytica, Netherlands, v.87, n.1, p.53-58, 1996.

5. Charron, C. Natural variation and functional analysis provide evidence for coevolution between plant elF4E and potyviral VPg. The Plant Journal, v. 54, p.56-68, 2008.

6. Dumas de Vaulx, R.; Chambonnet, D.; Pochard, E. Culture in vitro d'anthéres de piment (Capsicum annuum L.) amélioration des taux d'obtention de plantes chez différents génotypes par des traitements á $+35^{\circ} \mathrm{C}$. Agronomie, v.1, n.10, p.859-864, 1981.

7. Dunwell, J.M. Haploids in flowering plants: origins and exploitation. Plant Biotechnology Journal, Reading, v. 8, p. 377-424, 2010.

8. Evans, D.A.; Sharp, W.R. Applications of somaclonal variation. Biotechnology, Winthrop, v.4, p.528-532, 1986.

9. Ferreira, M.E.; Willians, P.H.; Osborn, T.C. RFLP mapping of Brassica napus using double haploid lines. Theoretical and Applied Genetics, Berlim, v.89, n.5, p.615-621, 1994.

10. Gébre-Selassie, K.; Marchoux, G.; Delecolle, B.; Pochard, E. Variabilité naturelle des souches du virus $Y$ de la pómme de terre dans les cultures de piment du Sud-Est de la France. Caractérisation et classification en pothotypes. Agronomie, v.5, p.621-630, 1985.

11. Gilbert, J.; McGuire, D.C. Root knot resistance in commercial type tomatoes in Hawaii. Proceedings of the American Society for Horticultural
Science, New York, v.60, p.401-411, 1952.

12. Gilbert, J.; McGuire, D.C. Inheritance of resistance to severe root knot form Meloidogyne incognita in commercial type tomatoes. Proceedings of the American Society for Horticultural Science, New York, v.68, p.437-442, 1956.

13. Gioria, R.; Braga, R.S.; Krause-Sakate, R.; Roullier, C.; Rosa, D.D.; Moura, M.F.; Souza-Dias, J.A.C.; Sawazaki, H.E.; Camargo, L.E.A.; Rezende, J.A.M. Breakdown of resistance in sweet pepper against Pepper yellow mosaic virus in Brazil. Scientia Agricola, Piracicaba v.66, n.2, p.267269, 2009.

14. Horsch, R.B.; Fry, J.E.; Hoffmann, N.L.; Eichholtz, D.; Rogers, S.G.; Fraley, R.T. A simple and general method for transferring genes into plants. Science, Washington, v.227, n.4691, p.1229-1231, 1984.

15. Inoue-Nagata, A.K.; Fonseca, M.E.N.; Resende, R.O.; Boiteux, L.S.; Monte, D.C.; Dusi, A.N.; Ávila, A.C.; Vander Vlugt, R.A.A. Pepper yellow mosaic virus, a new potyvirus in sweet pepper, Capsicum annuum. Archives of Virology, Wien, v.147, n.4, p.849-855, 2002.

16. Kogh, F.; Haagen-Smit, A.J.; Erxleben, H. Über ein neues auxin ('Hetero-auxin') aus harn. Zeitschrift fuer Physiologische chemie, Berlim, v.228, p.90-103, 1934

17. Krikorian, A.D.; Berquam, D.L. Plant cell and tissue culture: the role of haberlandt. Botanical Review, v.35, p.59-88, 1969.

18. Maluf, W.R.; Caldas, L.S.; Toma-Braghini, M.; Corte, R.D.; Ikuta, H.; Kunieda-Yabase, M. Alternatives to current tropical cauliflower hybrids obtained from self-incompatible inbred lines. Revista Brasileira de Genética, Ribeirão Preto, v.12, n.2, p.331-345, 1988.

19. Maluf, W.R.; Corte, R.D.; Toma-Braghini, M.; Caldas, L.S.; Ikuta, H; Kunieda-Yabase, M. Early testing of parental combining ability in tropical cauliflower hybrids. Revista Brasileira de Genética, Ribeirão Preto, v.11, n.4, p.893-903, 1988.

20. Morrison, R.A.; Evans, D.A. Bells sweet: plant variety protection certificate $\mathrm{N}^{\circ}$ 9700124. 1988.

21. Moura, M.F., Mituti, T., Marubayashi, J. M., Gioria, R., Kobori, R.F., Pavan, M.A., Silva, N., Krause-Sakate, R. A classification of Pepper yellow mosaic virus isolates into pathotypes. European Journal Plant Pathology Netherlands, v.131, n.4, p.549-552, 2011.

22. Nagai, H.; Costa, A.S. Four new pepper varieties resistant to virus $Y$ in Brazil. In: Meeting on Genetics and Breeding of Capsicum, n.1, 1972, Turin. Proceedings. Turin: Eucarpia, 1972, p.283-287.

23. Nagai, H. Pimentão, pimenta doce e pimenta In: Furlani, A.M.C; Viegas, G.(Orgs). O melhoramento de plantas no Instituto Agronômico. Instituto Agronômico, Campinas, p.276-294, 1993.

24. Shmykova, N.A.; Pyshnaya, O.N.; Shumilina, D.V.; Dzhos, E.A. Morphological characteristics of double haploid plants of pepper produced using microspore/anther in vitro culture of the interspecies hybrids of Capsicum annuum L. and C. chinense Jacq. Russian Agricultural Sciences, Moscow, v.40, n.5, p. 21-25, 2014.

25. Truta, A.A.C., Souza, A.R.R., Nascimento, A.V.S., Pereira, R.C.,Pinto, C.M.F., Brommonschenkel, S.H., Carvalho, M.G., Zerbini, M. Identidade e propriedades de isolados de potyvirus provenientes de Capsicum spp. Fitopatologia Brasileira, Brasília, v.29, n.2, p.160-168, 2004.

26. Van Overbeek, J., Conklin, M.E., Blakeslee, A.F. Factors in coconut milk essential for growth and development of very young Datura embryos. Science, Washington, v.94, n.2441, p.305-351, 1941.

27. White, P.R. Potentially unlimited growth of excised plant callus in an artificial nutrient. American Journal of Botany, New York, v.26, n.2, p.59-64, 1939. 